\title{
A narrative review of driving pressure as a monitoring indicator during mechanical ventilation with spontaneous breathing
}

\author{
Xue-Shu Yu' ${ }^{1}$, Jing-Ye Pan $^{2}$ \\ ${ }^{1}$ Department of Intensive Care, School of Wenzhou Medical University, Wenzhou, China; ${ }^{2}$ Department of Intensive Care, The First Affiliated \\ Hospital of Wenzhou Medical University, Wenzhou, China \\ Contributions: (I) Conception and design: All authors; (II) Administrative support: None; (III) Provision of study materials or patients: XS Yu; (IV) \\ Collection and assembly of data: All authors; (V) Data analysis and interpretation: All authors; (VI) Manuscript writing: All authors; (VII)Final \\ approval of manuscript: All authors. \\ Correspondence to: Jing-Ye Pan. The First Affiliated Hospital of Wenzhou Medical University, Wenzhou, China. Email: wmupanjingye@126.com.
}

\begin{abstract}
The mortality of acute respiratory distress syndrome (ARDS) remains high, and mechanical ventilation $(\mathrm{MV})$ is an essential means of treatment. During MV, people realize the benefits of spontaneous breathing and the disadvantages of uncontrolled spontaneous breathing. Current methods of monitoring spontaneous breathing include oesophageal manometry, P0.1, and diaphragm function monitoring. However, these methods have limitations and deficiencies. The driving pressure is a new indicator that reflects the strain of the lung, which indicates the volumetric injury of the lung and is independently associated with mortality in ARDS patients. Moreover, in recent studies, driving pressure monitoring has been shown to be feasible in assisted support ventilation. This review summarizes the current state of spontaneous breathing and examines whether it is convenient to monitor driving pressure during spontaneous breathing to achieve lung protection ventilation.
\end{abstract}

Keywords: Spontaneous breathing; mechanical ventilation (MV); driving pressure; acute respiratory distress syndrome (ARDS); ventilator-induced lung injury

Submitted Sep 03, 2019. Accepted for publication Jul 28, 2020.

doi: 10.21037/apm-19-284

View this article at: http://dx.doi.org/10.21037/apm-19-284

\section{Introduction}

Acute respiratory distress syndrome (ARDS) is a major global public health problem. The mortality of ARDS is very high at approximately $40 \%$ (1). However, treatment measures are limited. Mechanical ventilation (MV) is one of the main treatment measures.

In recent years, sedation and paralysis have led to a greater understanding of the adverse effects of $M V$ in patients, and assisted spontaneous ventilation has received attention $(2,3)$. Spontaneous breathing can reduce neuromuscular damage, redistribute pulmonary blood flow, and improve oxygenation $(4,5)$. In contrast, uncontrolled spontaneous breathing increased ventilation heterogeneity and redistributed, and the inspired tidal volume (VT) led to self-inflicted lung injury $(6,7)$. Therefore, monitoring during spontaneous breathing is vital and indispensable. Recent studies have also highlighted how the driving pressure [i.e., ratio of VT to respiratory compliance (Crs), and when there is no spontaneous compliance, it is equal to plateau pressure (Pplat) minus positive end-expiratory pressure (PEEP)] affects the prognosis of mechanically ventilated ARDS patients (8). Driving pressure represents the strain of the lung and the target for limiting the inspiratory volume. Unfortunately, researchers generally believe that Pplat and driving pressure can only be accurately measured during paralysis. Moreover, if we obtain airway pressure without oesophageal manometry, the pressure is underestimated. Interestingly, with the development of MV, studies have shown that we could overcome these shortcomings (9).

In this review, we briefly describe the benefits and 
damages of spontaneous breathing during $M V$, with a focus on using driving pressure for lung protection ventilation during spontaneous breathing. We present the following article in accordance with the Narrative Review Reporting Checklist (available at http://dx.doi.org/10.21037/apm19-284).

\section{Methods}

Information used to write this paper was collected from the PubMed databases using the following key words: spontaneous breathing; monitor; driving pressure; ventilator-induced lung injury.

\section{Discussion}

\section{Pros and cons of spontaneous breatbing}

It has been shown that spontaneous breathing improves ventilation-perfusion matching, reduces diaphragm damage, and improves oxygenation $(2,10)$. Recently, Corral reported that diaphragm activity was closely related to the occurrence and development of ventilator-induced diaphragmatic dysfunction (VIDD) (3) and suggested that if a certain level of spontaneous breathing was maintained during MV, VILI could be reduced due to diaphragm unloading by reducing the harmful effects of controlled mechanical ventilation (CMV). However, spontaneous breathing also has adverse effects during MV, as evidenced by several studies. Due to the specificity of the lungs of patients with ARDS, VT can be out of control, and uneven distribution can be aggravated by negative pleural pressure. Additionally, pleural pressure combined with alveolar pressure may also aggravate pulmonary interstitial oedema $(11,12)$. Moreover, these adverse effects might aggravate lung injury. Controlling VTT and transpulmonary pressure can reduce barotrauma and volumetric injuries and thus reduce the damage caused by increased spontaneous effort (13). Interestingly, Yoshida et al. recently showed that only when the level of spontaneous breathing effort and local-dependent lung pressure are low could the risk of spontaneous breathing be eliminated by limiting VT and oesophageal pressure in the volumecontrolled (VC) mode (11). In VC, spontaneous efforts to produce locally dependent pulmonary pressure increase, even at the same VT and oesophageal pressure settings, resulting in more than twice the amount of ventilation and tidal recruitment in the posterior region. Oesophageal pressure cannot accurately assess local pleural pressure when there is a spontaneous effort in patients with ARDS. More interestingly, spontaneous breathing does not contribute to severe lung injury but instead contributes to mild lung injury.

Indeed, Papazian et al. reported that early administration of neuromuscular blockers improves outcomes in patients with severe ARDS (14). However, there are still different perspectives on whether early continuous neuromuscular blockade is beneficial. More recently, in an RCT containing 1,006 patients with moderate-to-severe ARDS, there was no significant difference in mortality between the continuous neuromuscular block group and the mild sedation group (15).

In summary, spontaneous breathing is beneficial in mild ARDS, but the case of moderate-to-severe ARDS. One of the possible causes is that there is proper spontaneous breathing in mild ARDS, while spontaneous breathing is out of control in moderate to severe cases, which suggests that spontaneous breathing can only have a real protective effect if it has better monitoring indicators.

\section{Spontaneous breathing monitoring}

To better understand the forces generated by the patient, it is necessary to monitor respiratory muscle activity. There have been many studies on respiratory muscle monitoring, including the following methods. (I) Oesophageal manometry: oesophageal manometry can assess respiratory effort during $\mathrm{MV}$, improve human-machine coordination, and serve as an indicator of weaning (16-18). It has considerable potential to improve clinical outcome in patients with ARDS as an early detector of the risk of lung injury from $M V$ and spontaneous effort (18). (II) P0.1: the occlusion pressure, which is the negative pressure generated when the occlusion is 0.1 seconds, is also called P0.1. This pressure can respond well to respiratory drive and thus prevent P-SILI and serve as an indicator of weaning (19). (III) Monitoring of diaphragm function: in addition to P0.1, the inspiratory effort can be estimated noninvasively by diaphragm ultrasound. Ultrasound measures of diaphragm thickening in the zone of apposition may be useful for predicting extubation success or failure during spontaneous breathing trials (20). Moreover, the neutrally adjusted ventilation assist mode gives patients corresponding support according to diaphragm electrical activity (21).

However, these monitoring methods have their own limitations; for example, oesophageal pressure is invasive 
and expensive, and due to the specificity of ARDS, oesophageal pressure only represents the average level of negative pleural pressure and cannot reflect the whole lung condition.

The monitoring of diaphragm function is easily interfered with by many factors and is prone to errors. More importantly, these monitoring methods only reflect respiratory muscle strength, and the patient's lung expansion is also under pressure provided by the ventilator. Excessive lung expansion is the most critical cause of VILI. Therefore, there is an urgent need for a reliable and straightforward indicator to comprehensively reflect the expansion of the lungs to prevent the occurrence of lung injury. The emergence of the driving pressure makes up for this deficiency.

\section{Development of driving pressure}

CT brings us closer to the real face of ARDS. According to the results of the CT examination, the concept of "baby lung" has been proposed (22). More importantly, the compliance and functional residual capacity of the baby lung are proportional (23), and VILI is related to its excessive stress and strain. To prevent VILI, we must limit VT based on the functional residual capacity of the baby's lungs rather than the ideal weight (24-26). Recently, Amato et al. reported that the Crs-standardized VT was a better predictor of prognosis in patients with ARDS than VT alone. The ratio of the two in the absence of the effect of spontaneous effort was defined as the driving pressure (8).

Subsequently, the LUNG SAFE study is a prospective study of ICUs in 50 countries. As a result, when the driving pressure is higher than $10 \mathrm{cmH}_{2} \mathrm{O}$, the mortality rate increases linearly (27). Similar results to these studies, a meta-analysis reported by Hiroko Aoyama that ARDS patients who underwent $M V$ at lower driving pressure had lower mortality (28).

In recent years, many pieces of evidence $(8,27-31)$ have shown that driving pressure might be one of the essential indicators of lung protection during MV. However, it still has many disadvantages; for example, driving pressure should be used during paralysis without spontaneous breathing, and it does not consider the effects of the chest wall $(32,33)$. However, Amato et al. found that in severe ARDS patients, the pressure to inflate the lungs mainly derives from the driving pressure, and the driving pressure might replace the transpulmonary driving pressure. Moreover, the cutoff of driving pressure was not explicit, and no RCT had indicated the feasibility of driving pressure. In any case, the concept of driving pressure means that we have a better understanding of protective ventilation.

\section{Application of driving pressure in spontaneous breathing}

MV combined with spontaneous breathing is a combination of positive pressure ventilation and negative pressure ventilation, but the essence is the same for lung expansion, so we believe that driving pressure can be used as a predictor for such patients. P0.1, the diaphragm point or the oesophageal pressure reaction are all related to muscle strength, and the driving pressure response is the result of the final force of the lung, that is, the strain of the lung. Therefore, monitoring the driving pressure may be more intuitive. However, a reliable driving pressure could be obtained correctly without spontaneous breathing, and spontaneous breathing efforts to produce pleural pressure could not be ignored. How could we accurately assess the driving pressure of patients with spontaneous breathing?

Zhou et al. measured the platform pressure by switching to the capacity control mode and then subtracted the previously monitored positive end-expiratory pressure (PEEP) from the platform pressure as the driving pressure in the airway pressure release ventilation (APRV) group. They found that early application of APRV was similar to driving pressure compared to low VT ventilation but improved oxygenation and Crs. Additionally, the platform pressure of the APRV group is lower, and the MV time and ICU residence time are shortened (34). Additionally, Tomas et al. also evaluated the driving pressure in the ARPV mode. They compared the effects of PEEP on lung inflammation in mild-to-moderate ARDS pig models with or without spontaneous breathing, with a limit of driving pressure less than $15 \mathrm{cmH}_{2} \mathrm{O}$ (35). However, Taylor et al. thought that the real driving pressure should be calculated as $\mathrm{P}_{\text {high }}$ - (intrinsic PEEP $+\mathrm{P}_{\text {low }}$ ). Otherwise, the DRIVING PRESSURE is overestimated in APRV mode because the effect of intrinsic PEEP is ignored (36).

Recently, Bellani et al. reported that a brief inspiratory hold during pressure-supported ventilation can achieve a relatively accurate Pplat and that the inspiratory effort does not significantly affect the airway pressure waveform, which is only noticeable when the inspiratory is interrupted. Moreover, inspiratory pauses during positive pressure ventilation with spontaneous breathing efforts result in 
increased pressure in the airway and increased platform pressure. Therefore, they suggest that in the case of spontaneous breathing, inspiratory hold can also be used to measure Pplat during pressure support ventilation (PSV), thereby deriving lung compliance and platform pressure (9). Whether we could obtain a relatively accurate platform pressure, it is essential to know which is the actual platform pressure, which reflects the extraordinary impact of VT and spontaneous breathing.

In addition to PSV, proportional assist ventilation with load-adjustable gain factors $(\mathrm{PAV}+)$ is a new mode of ventilation in which the ventilator provides proportion assistance to the muscle strength by calculating the muscle strength required to overcome elastic and airway resistance during spontaneous breathing; these are updated several times per minute during PAV ventilation (37). We used the driving pressure formula (equal to $\mathrm{Vt} / \mathrm{Crs}$ ) to obtain the dynamic driving pressure directly. Recently, Vaporidi et al. calculated driving pressure as the $\mathrm{Vt}$-to-Crs ratio when treating PAV+ patients. The results show that high driving pressure is closely related to low compliance. More importantly, when the compliance is less than $30 \mathrm{~mL} /$ $\mathrm{cmH}_{2} \mathrm{O}$, a driving pressure greater than $15 \mathrm{cmH}_{2} \mathrm{O}$ will occur. Unfortunately, similar to other research studies, those authors did not evaluate chest wall mechanics and intrinsic PEEP yet (38).

The above studies have shown that people have begun to evaluate the driving pressure during $M V$ in the presence of spontaneous breathing, and it seems that the driving pressure can be conveniently and accurately assessed, although there is still much to be discussed.

\section{Conclusions}

In summary, this discussion of the advantages and disadvantages of spontaneous breathing reflects a deeper understanding of respiratory physiology, and the debate regarding driving pressure also reflects people's more indepth knowledge of VILI.

Driving pressure is a useful and valid measure of lung strain in MV patients with spontaneous breathing. Monitoring the driving pressure may be more conducive to lung protection ventilation. Since this parameter is now readily available, we can apply it to clinical practice.

\section{Acknowledgments}

Funding: This work was supported by the National
Natural Science Foundation of China (grant numbers 81671968 to JYP).

\section{Footnote}

Reporting Checklist: The authors have completed the Narrative Review Reporting Checklist. Available at http:// dx.doi.org/10.21037/apm-19-284

Conflicts of Interest: All authors have completed the ICMJE uniform disclosure form (available at http://dx.doi. org/10.21037/apm-19-284). The authors have no conflicts of interest to declare.

Ethical Statement: The authors are accountable for all aspects of the work in ensuring that questions related to the accuracy or integrity of any part of the work are appropriately investigated and resolved.

Open Access Statement: This is an Open Access article distributed in accordance with the Creative Commons Attribution-NonCommercial-NoDerivs 4.0 International License (CC BY-NC-ND 4.0), which permits the noncommercial replication and distribution of the article with the strict proviso that no changes or edits are made and the original work is properly cited (including links to both the formal publication through the relevant DOI and the license). See: https://creativecommons.org/licenses/by-nc-nd/4.0/.

\section{References}

1. Bellani G, Laffey JG, Pham T, et al. Epidemiology, Patterns of Care, and Mortality for Patients With Acute Respiratory Distress Syndrome in Intensive Care Units in 50 Countries. JAMA 2016;315:788-800.

2. Levine S, Nguyen T, Taylor N, et al. Rapid disuse atrophy of diaphragm fibers in mechanically ventilated humans. $\mathrm{N}$ Engl J Med 2008;358:1327-35.

3. Marin-Corral J, Dot I, Boguna M, et al. Structural differences in the diaphragm of patients following controlled vs assisted and spontaneous mechanical ventilation. Intensive Care Med 2019;45:488-500.

4. Grasso F, Engelberts D, Helm E, et al. Negative-pressure ventilation: better oxygenation and less lung injury. Am J Respir Crit Care Med 2008;177:412-8.

5. Carvalho AR, Spieth PM, Pelosi P, et al. Pressure support ventilation and biphasic positive airway pressure improve oxygenation by redistribution of pulmonary blood flow. 
Anesth Analg 2009;109:856-65.

6. Yoshida T, Torsani V, Gomes S, et al. Spontaneous effort causes occult pendelluft during mechanical ventilation. Am J Respir Crit Care Med 2013;188:1420-7.

7. Yoshida T, Nakahashi S, Nakamura MAM, et al. Volumecontrolled Ventilation Does Not Prevent Injurious Inflation during Spontaneous Effort. Am J Respir Crit Care Med 2017;196:590-601.

8. Amato MB, Meade MO, Slutsky AS, et al. Driving pressure and survival in the acute respiratory distress syndrome. $\mathrm{N}$ Engl J Med 2015;372:747-55.

9. Bellani G, Grassi A, Sosio S, et al. Plateau and driving pressure in the presence of spontaneous breathing. Intensive Care Med 2019;45:97-8.

10. Demoule A, Clavel M, Rolland-Debord C, et al. Neurally adjusted ventilatory assist as an alternative to pressure support ventilation in adults: a French multicentre randomized trial. Intensive Care Med 2016;42:1723-32.

11. Yoshida T, Uchiyama A, Matsuura N, et al. The comparison of spontaneous breathing and muscle paralysis in two different severities of experimental lung injury. Crit Care Med 2013;41:536-45.

12. Thille AW, Mauri T, Talmor D. Update in Critical Care Medicine 2017. Am J Respir Crit Care Med 2018;197:1382-8.

13. Slutsky AS, Ranieri VM. Ventilator-induced lung injury. $N$ Engl J Med 2013;369:2126-36.

14. Papazian L, Forel JM, Gacouin A, et al. Neuromuscular blockers in early acute respiratory distress syndrome. $\mathrm{N}$ Engl J Med 2010;363:1107-16.

15. Moss M, Huang DT, Brower RG, et al. Early Neuromuscular Blockade in the Acute Respiratory Distress Syndrome. N Engl J Med 2019;380:1997-2008.

16. Akoumianaki E, Maggiore SM, Valenza F, et al. The application of esophageal pressure measurement in patients with respiratory failure. Am J Respir Crit Care Med 2014;189:520-31.

17. Mauri T, Yoshida T, Bellani G, et al. Esophageal and transpulmonary pressure in the clinical setting: meaning, usefulness and perspectives. Intensive Care Med 2016;42:1360-73.

18. Yoshida T, Brochard L. Esophageal pressure monitoring: why, when and how? Curr Opin Crit Care 2018;24:216-22.

19. Telias I, Damiani F, Brochard L. The airway occlusion pressure (P0.1) to monitor respiratory drive during mechanical ventilation: increasing awareness of a not-sonew problem. Intensive Care Med 2018;44:1532-5.
20. DiNino E, Gartman EJ, Sethi JM, et al. Diaphragm ultrasound as a predictor of successful extubation from mechanical ventilation. Thorax 2014;69:423-7.

21. Carteaux G, Cordoba-Izquierdo A, Lyazidi A, et al. Comparison Between Neurally Adjusted Ventilatory Assist and Pressure Support Ventilation Levels in Terms of Respiratory Effort. Crit Care Med 2016;44:503-11.

22. Gattinoni L, Caironi P, Pelosi P, et al. What has computed tomography taught us about the acute respiratory distress syndrome? Am J Respir Crit Care Med 2001;164:1701-11.

23. Gattinoni L, Pesenti A, Baglioni S, et al. Inflammatory pulmonary edema and positive end-expiratory pressure: correlations between imaging and physiologic studies. J Thorac Imaging 1988;3:59-64.

24. Gattinoni L, Pesenti A. The concept of "baby lung". Intensive Care Med 2005;31:776-84.

25. Chiumello D, Carlesso E, Brioni M, et al. Airway driving pressure and lung stress in ARDS patients. Crit Care 2016;20:276.

26. Xie J, Jin F, Pan C, et al. The effects of low tidal ventilation on lung strain correlate with respiratory system compliance. Crit Care 2017;21:23.

27. Laffey JG, Bellani G, Pham T, et al. Potentially modifiable factors contributing to outcome from acute respiratory distress syndrome: the LUNG SAFE study. Intensive Care Med 2016;42:1865-76.

28. Aoyama H, Pettenuzzo T, Aoyama K, et al. Association of Driving Pressure With Mortality Among Ventilated Patients With Acute Respiratory Distress Syndrome: A Systematic Review and Meta-Analysis. Crit Care Med 2018;46:300-6.

29. Villar J, Martin-Rodriguez C, Dominguez-Berrot AM, et al. A Quantile Analysis of Plateau and Driving Pressures: Effects on Mortality in Patients With Acute Respiratory Distress Syndrome Receiving Lung-Protective Ventilation. Crit Care Med 2017;45:843-50.

30. Guérin C, Papazian L, Reignier J, et al. Effect of driving pressure on mortality in ARDS patients during lung protective mechanical ventilation in two randomized controlled trials. Crit Care 2016;20:384.

31. Das A, Camporota L, Hardman JG, et al. What links ventilator driving pressure with survival in the acute respiratory distress syndrome? A computational study. Respir Res 2019;20:29.

32. Baedorf Kassis E, Loring SH, Talmor D. Mortality and pulmonary mechanics in relation to respiratory system and transpulmonary driving pressures in ARDS. Intensive Care Med 2016;42:1206-13. 
33. De Jong A, Cossic J, Verzilli D, et al. Impact of the driving pressure on mortality in obese and non-obese ARDS patients: a retrospective study of 362 cases. Intensive Care Med 2018;44:1106-14.

34. Zhou Y, Jin X, Lv Y, et al. Early application of airway pressure release ventilation may reduce the duration of mechanical ventilation in acute respiratory distress syndrome. Intensive Care Med 2017;43:1648-59.

35. Kiss T, Bluth T, Braune A, et al. Effects of Positive End-Expiratory Pressure and Spontaneous Breathing Activity on Regional Lung Inflammation in Experimental Acute Respiratory Distress Syndrome. Crit Care Med 2019;47:e358-65.

36. Taylor D, Camporota L, Zhou Y, et al. Estimation of true driving pressure during airway pressure release ventilation: Discussion on "Early application of airway pressure release ventilation may reduce the duration of mechanical ventilation in acute respiratory distress syndrome". Intensive Care Med 2018;44:1364-5.

37. Kondili E, Prinianakis G, Alexopoulou C, et al. Respiratory load compensation during mechanical ventilation--proportional assist ventilation with loadadjustable gain factors versus pressure support. Intensive Care Med 2006;32:692-9.

38. Vaporidi K, Psarologakis C, Proklou A, et al. Driving pressure during proportional assist ventilation: an observational study. Ann Intensive Care 2019;9:1.

Cite this article as: Yu XS, Pan JY. A narrative review of driving pressure as a monitoring indicator during mechanical ventilation with spontaneous breathing. Ann Palliat Med 2020;9(5):3522-3527. doi: 10.21037/apm-19-284 